\title{
Air Pollution and Health Status in Sub-Sahara Africa (SSA)
}

\author{
Uche Abamba Osakede ${ }^{1 *} \quad$ Patricia Iyore Ajayi ${ }^{2}$ \\ 1.Department of Economics, Bowen University, P.M.B 284, Iwo Osun State, Nigeria \\ 2.Department of Economics, University of Ibadan, Ibadan, Nigeria
}

\begin{abstract}
Air pollution is projected to be higher in low-income countries most of which are in sub-Sahara Africa (SSA) than other parts of the world; yet not many studies provide evidence relating air pollution with health condition in the region. This paper contributes to empirical literature evidence in this regard by examining the effect of air pollution measured using Carbon dioxide emission $\left(\mathrm{CO}_{2}\right)$ on life expectancy and infant mortality rates in the SSA region. The Fixed and Random effects model were fitted to a panel of 44 countries from the period 1960 to 2017. The results suggest that poor air quality contributes to existing low health status in SSA inducing a fall in life expectancy and rise in infant mortality rates. The evidence showed that a $1 \%$ increase in $\mathrm{CO}_{2}$ emission leads to a fall in life expectancy at birth by approximately 1.5 years and increase in infant death by about $0.1 \%$. Findings indicate that existing poor health outcome in SSA are connected to poor air quality. In the bid to achieve the Sustainable Development Goal (SDG) on health, there is need for governments in the region to focus on reducing air pollution, particularly in achieving significant fall in infant deaths and improvements in life span.
\end{abstract}

Keywords: Air pollution, Health Status, Fixed and Random effects model, SSA

DOI: $10.7176 / \mathrm{JESD} / 10-22-03$

Publication date: November $30^{\text {th }} 2019$

\section{Background}

Energy use is vital for achieving economic growth through the workings of the industrial sector. Ironically, the use of energy inevitably produces toxic substances that are harmful to the environment and human health (Zerbo 2015). This specifically relates with poor air quality associated with emissions from non-clean energy sources. For instance, emissions from residential energy use, constitute serious health problems in China and India. In some other places like the United States, emissions from traffic and power generation are quite hazardous (Lelieveld $e t$ al. 2015). The effect of air pollution is expected to rise more dramatically in less developed economies where there is poor management of policies to curb emissions. From the recent global burden of disease modeling, the effects are projected to be higher in low-income countries most of which are in sub-Sahara Africa (SSA) than other parts of the world (Landrigan et al 2018).

In terms of the effect of air quality on health status, empirical findings show evidence of an inverse relationship. In India, the emission of carbon dioxide $\left(\mathrm{CO}_{2}\right)$, Sulphur dioxide $\left(\mathrm{SO}_{2}\right)$ and nitrogen oxide $(\mathrm{NO})$ induced illnesses such as chronic bronchitis, respiratory problem, asthma and cardiovascular diseases (Mukhopadhyaya \& Forssellb 2005). There are also indications that air pollution is a significant cause of premature mortality (Lelieveld et al. 2015). Estimates show that outdoor air pollution can induce as much as about 3.3 million premature deaths per year (Lelieveld et al. 2015). Findings by Li et al. (2015) also showed that outdoor activity may not improve health where exercise takes place in areas with high air pollution levels. Persons who exercise in highly polluted areas rather than have improved health conditions, experience high risk of health problems, such as asthma, heart and lung pathologies. In China, Zang et al (2015) associated air quality with subjective well-being by inducing shorter-term hedonic happiness and increase in the rate of depressive symptoms. Sustained exposure to air pollution is also a cause of shorter life span, particularly in connection with mortality from cardiorespiratory illness (Ebenstein et al. 2017). Nakao et al. (2017) provides similar evidence showing that air pollution from coal results to a deterioration of health-related quality of life (HR-Qol) for Mongolian adults in Ulaanbaatar. Liu et al (2018) provides similar evidence showing adverse effect of air pollution on public health in China.

Where individuals are exposed to air pollution, the effects are not only seen on poor health conditions but also on reduced productivity of labour which further worsens payment ability for failing health condition. (Pitt $e t$ al. 2006). In Chile, Montt (2018) suggests that air pollution contributes not only to a fall in labour activity but also to gender difference in labour supply. It induces significant reduction in working hours of women especially for those with children. Recent finding by Qi et a.l (2018) showed that aside inducing significant increase in the likelihood of being diagnosed with respiratory and cardiovascular diseases, poor air quality also has significant adverse impact on cognitive abilities, including short-term memory and mathematical reasoning.

In Thailand, evidence shows that improvement in air quality translates to better health. It was shown that a $20 \%$ fall in ambient air pollution, reduced annual mortality particularly related to respiratory and cardiovascular illnesses by as much as about 25\% (Pinichka et al. 2017). Findings for developed countries like the United States also showed improvements in health with a fall in air pollution (Correia et al. 2013)

Aside the rise in illness prevalence, poor air quality also raises health spending. Evidence provided by Romley 
et al. (2010) showed that poor air quality raises direct health care costs resulting from complications and also imposes substantial burden on both public and private health insurers mainly in developed economies (Romley et al. 2010. Given the various forms of air pollution, it is shown that the cost burden of health in association with $\mathrm{CO}_{2}$ is highest (Yahaya 2016). This is suggestive of more harmful effects of $\mathrm{CO}_{2}$ emission in comparison to other forms of air pollution.

In examining the effect of air pollution on health outcome, various methods have been applied in the literature. Differences in methods used often follows from the type of data adopted. Panel data studies for instance, commonly make use of the fixed and random effects model. The Fixed and Random effects model were used by Ozdamar (2018) in examining health status and air quality in Europe. Zang et al. (2015) also made use of the fixed effect model to examine the impact of air quality on subjective well-being using survey data for 162 counties in China. Montt (2018) also made use of the fixed effect model to examine the effect of air pollution on labour supply across gender using quarterly employment survey data between 1997 and 2016 in Chile. The fixed effect model controls for time invariant sample unobservable determinants of health outcomes. It accounts for bias that would result in study findings due to intrinsic differences in selected countries or cross sections such as climatic conditions, genetic composition of the population, health related behavior, policies and institutions. These variables are generally constant over time but vary across cross sections (Wooldridge, 2002; Plumper and Neumayer 2013; Maisonneuve et al. 2017). The fixed effect model can be used to control for endogeneity in panel data due to a time-invariant omitted variable (Cameron and Trivedi, 2005). The specification assumes that there is no correlation across any error terms. Sometimes, year dummies are introduced into the fixed effect model to capture trends and year specific shocks such as drought, epidemic conditions, among others (Rajkumar \& Swaroop 2008; Farag et al. 2013) The random effect model on the other hand allows for correlation across the error terms for each country in a panel data analysis. In this case, the individual effects are conceptualized as uncorrelated with the time variant predictor variables in the model and hence there are no concerns for endogeneity issues (Baltagi et al. 2007; Rajkumar \& Swaroop 2008). Choice of the most appropriate approach is determined using the Hausman specification test (Hausman 1978). Where there is no spatial serial dependence of the error terms, the random effect estimation is considered more appropriate otherwise the fixed effect model is preferred. (Baltagi et al. 2007).

Analytical techniques used for country specific studies generally differ from those applied for panel data analysis. For instance, in examining the impact of indoor air pollution on health outcome and cognitive abilities, Qi et al. (2018) made use of the propensity score matching that enables examining the likelihood of occurrence of health problems from exposure to air pollution in China. The propensity score matching usually incorporates a control and treatment group. Where the later are persons exposed to poor air quality. Using similar data set, Correia et al. (2013) made use of the first-difference linear regression models to examine the effect of air pollution control on life expectancy in the United States. Use of this technique is most appropriate for studies with small time points. This study covered 545 counties in the United States with separate analysis for each country. Using data for the periods 2000 to 2007, Nakao et al. (2017) made use of the logistic regression to examine the effect of air pollution on health-related quality of life (HR-Qol) of Mongolian adults living in Ulaanbaatar: The logistic regression model is applied mainly when the dependent variable is dichotomous and the data set is cross sectional. The logistic regression model was also applied by Liu et al. (2018) in examining the health effects of air pollution in China. Ebenstein et al. (2017) made use of the Ordinary least square (OLS) regression technique in examining the impact of sustained exposure to air pollution on life expectancy in China. The OLS is usually applied where the dependent variable is continuous and the data set follows specific assumption for an OLS technique (Gujarati 2004).

Overall, exposure to air pollution constitutes significant health risk for both industrialized and developing economies. Existing population expansion and urbanization of developing economies as they tread on the path to development are also suggestive of stronger effects of poor air quality on health and related indices (Mannucci \& Franchini 2017). However, not much empirical evidence is provided for the effect of air pollution in developing countries such as those in SSA. This particularly, is interesting given poor management of policies to curb emission in the region. This study is motivated by the paucity of findings on the effect of air pollution on health outcome in SSA region and seeks to provide empirical evidence in this regard.

\section{Methodology}

\subsection{Data and variables}

The study pooled cross-section and annual time series data from 1960 to 2017 for 44 countries in SSA. The data used in the empirical analysis were sourced from the World Development Indicators (WDI) data set provided by the World Bank (World Bank 2018).

The study measures outdoor air pollution using carbon dioxide $\left(\mathrm{CO}_{2}\right)$ emission in kilotons. The choice of $\mathrm{CO}_{2}$ follows from availability of data for a panel data study of this type and suggestive strong effects on health indicators (Yahaya 2016). Health status indicators are captured using life expectancy at birth and infant mortality rate. Life expectancy at birth and infant mortality are used as measures of health mainly because long-term improvements in the health status of a population are best reflected in infant mortality and life expectancy rates. In addition, 
improvements in health are commonly deciphered in longer years of life and fall in infant death (Gupta \& Mitre 2004). Life expectancy at birth was measured in years as total life expectancy in years and infant mortality rate in per 1,000 live births.

Specific variables that are considered vital for modelling population health status includes; age, sex, hereditary factors, lifestyle, social and community influences, living and working condition, socio-economic factors, cultural and environmental conditions (Dahlgren \& Whitehead 1991). However, difficulty in measurement and obtaining data for some of the variables, limits predictors of health used in this study to living and working conditions using income as a proxy, literacy rate and labor force participation to capture social and community influences. Literacy rate was examined separately for males and females. This is to further capture cultural characteristics that sometimes reflect in differences in male and female education. Fertility rate is used as a proxy for cultural factors while environmental conditions are captured using $\mathrm{CO}_{2}$ as a measure of air quality.

\subsection{The model}

In line with most panel data studies, this study made use of a standard panel regression approach using the fixed and random effects model to fit the data set. The general specification for the model is stated as:

$Y_{i t}=\delta_{y x t} X_{i t}+\varphi_{y z t} Z_{i}+\pi_{i}+\mu_{i t}$

Where $Y_{i t}$ is the value of the dependent variable for the $i$ th case in the sample at the $t$ th time period, $X_{i t}$ is the vector of time-varying covariates for the $i$ th at the $t$ th time period, $\delta_{y x t}$ is the row vector of coefficients that give the impact of $X_{i t}$ on $Y_{i t}$ at time $t, Z_{i}$ is the vector of observed time-invariant covariates for the $\mathrm{i}$ th case with $\varphi_{y z t}$ its row vector of coefficients at time t. $\pi_{i}$ is a scalar of all other latent time-invariant variables that influence $Y_{i t}$, and $\varepsilon_{i t}$ is the random disturbance for the $i$ th case at the $t$ th time period with $E\left(\mu_{i t}\right)=0$ and $E\left(\mu_{i t}^{2}\right)=\mu_{t}^{2}$

For the fixed effects model, it is assumed that the time invariant unit specific effect is correlated with the time variant explanatory variables $X_{i t}$ while the random effects model assumes that the time invariant unit specific effect is uncorrelated with the time variant explanatory variables $X_{i t}$ (Bollen and Brand 2008).

The fixed and random effects model were fitted to the model specification for life expectancy and infant mortality. The econometric model estimated for life expectancy and infant mortality is specified as:

LExpec $_{i t}=\propto_{1}+\propto_{2}$ LNCO $_{2 i t}+\propto_{3} L N G D P_{i t}+\propto_{4}$ Flr $_{i t}+\propto_{5}$ Mlr $_{i t}+\propto_{6}$ lf $_{i t}++\propto_{7} F r_{i t}+\varepsilon_{i t}$

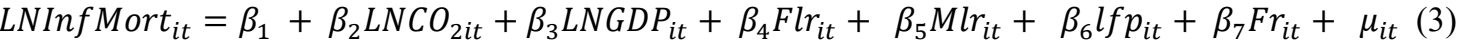

Where $\mathrm{i}=1 \ldots \mathrm{N}$ denotes a cross-section index of countries, $\mathrm{t}=1, \ldots, \mathrm{T}$ denotes the time-series index. The dependent variable in Equation (2) LExpec, is life expectancy at birth and in equation (3) LnInfMort, is infant mortality per 1,000 live births measured in natural logarithm. $\mathrm{LNCO}_{2}$, is air pollution expressed as natural logarithms of carbon emission. $L N G d p$, is the logarithmic value of real GDP. Flr, is female literacy rate as a percentage of females ages 15 and above. $M l r$, represents male literacy rate as a percentage of males ages 15 and above. $l f p$, is labour force participation as a percentage of total population ages 15 and above while $F r$ represents total fertility rate (births per woman).

The expected signs of the parameters in equation 3 are: $\propto_{1} \neq 0 ; \propto_{2}<0 ; \propto_{3}>0 ; \propto_{4}>0 ; \propto_{5}>0 ; \propto_{6}>0 ; \propto_{7}<$ 0 ; and in equation $4: \beta_{1} \neq 0 ; \beta_{2}>0 ; \beta_{3}<0 ; \beta_{4}<0 ; \beta_{5}<0 ; \beta_{6}<0 ; \beta_{7}>0$;. The estimated coefficients of variables expressed as natural logarithms are interpreted in percentage values. Infant mortality rate is logged in order to normalize the data. This is because the histogram for infant mortality is slightly skewed to the right ${ }^{1}$. Carbon emission and GDP are also logged as their log value gives better result in terms of expected sign and reduces the magnitude of the coefficient making it easy for interpretation especially for GDP. The other independent variables are not logged as they are already in percentage values except for fertility rate.

The study estimates the Random effects model using the Generalized Least Squares (GLS) while fixed effects model was estimated as a within regression using ordinary least squares. The choice of the model that best suits the data is carried out using the Hausman specification. Stata statistical software package was used in the analysis.

\section{Results}

Table 1 presents descriptive statistics for the variables used in the study. The figures from the table shows that in SSA average life expectancy is approximately 51 years. Infant deaths per 1,000 live births had a mean of about 95 .

\footnotetext{
${ }^{1}$ See appendix for histogram,
} 
Table 1 Descriptive statistics

\begin{tabular}{|c|c|c|c|c|c|c|}
\hline Variable & Description & Observation & Mean & Std dev & Min & Max \\
\hline LExpec & $\begin{array}{l}\text { Life expectancy at birth } \\
\text { (total) }\end{array}$ & 2773.00 & 51.07 & 8.54 & 27.61 & 74.39 \\
\hline InfMort & $\begin{array}{l}\text { Infant mortality per } 1,000 \\
\text { live births }\end{array}$ & 2528.00 & 94.51 & 41.55 & 11.90 & 222.00 \\
\hline $\mathrm{CO}_{2}$ & $\begin{array}{l}\mathrm{CO}_{2} \text { Emissions in } \\
\text { Kilotons }\end{array}$ & 2518.00 & 9602.25 & 47385.80 & -80.67 & 503112.40 \\
\hline GDP & $\begin{array}{l}\text { GDP at } 2010 \text { Constant US } \\
\text { Dollars }\end{array}$ & 2308.00 & $17,300,000,000.00$ & $49,300,000,000.00$ & $\begin{array}{l}112,000,00 \\
0.00\end{array}$ & $\begin{array}{l}464,000,000,0 \\
00.00\end{array}$ \\
\hline flr & $\begin{array}{l}\text { Literacy rate (Female) } \\
\text { (percentage of literate } \\
\text { females ages } 15 \text { and } \\
\text { above) }\end{array}$ & 178.00 & 49.00 & 26.45 & 3.18 & 94.45 \\
\hline Mlr & $\begin{array}{l}\text { Literacy rate (Male) } \\
\text { (percentage of literate } \\
\text { males ages } 15 \text { and above) }\end{array}$ & 178.00 & 64.67 & 21.20 & 13.51 & 95.40 \\
\hline lfp & $\begin{array}{l}\text { Labor force participation } \\
\text { rate total ILO estimate }\end{array}$ & 1343.00 & 68.62 & 11.70 & 42.36 & 91.54 \\
\hline fr & $\begin{array}{l}\text { Fertility rate (No of births } \\
\text { per woman) }\end{array}$ & 2760.00 & 6.00 & 1.25 & 1.36 & 8.46 \\
\hline
\end{tabular}

Source: Authors' computation from WDI (2018)

Emissions of $\mathrm{CO}_{2}$ is approximately 9,602 kilotons. Figures for real GDP show an average value of about US $\$ 17.3$ billion. While the proportion of females aged 15 and above who are literate are about $49 \%$ on average, that for males are approximately $65 \%$. Labor force participation rate is estimated to be approximately $69 \%$ and the number of births per woman is 6 on the average.

Results for the effect of $\mathrm{CO}_{2}$ emission on health status are reported in Tables 2 and 3 for life expectancy at birth and infant mortality rate respectively. While the results favored the fixed effect model for the life expectancy analysis and random effects for infant mortality, findings for both the fixed and random effect models were reported for comparison purposes and to allow for robustness of results.

Table 2 Effects of air pollution on life expectancy at birth (years)

\begin{tabular}{|c|c|c|}
\hline Variables & $\begin{array}{l}\text { Fixed effects within regression } \\
\text { model }\end{array}$ & GLS-random effects model \\
\hline $\mathrm{LNCO}_{2}$ & $\begin{array}{l}-1.4906^{* *} \\
(0.7824)\end{array}$ & $\begin{array}{l}-1.5594^{* *} \\
(0.7546)\end{array}$ \\
\hline LNGDP & $\begin{array}{l}0.7417 \\
(0.8732)\end{array}$ & $\begin{array}{l}0.8271 \\
(0.8445)\end{array}$ \\
\hline flr & $\begin{array}{l}-0.1482 * * * \\
(0.0542)\end{array}$ & $\begin{array}{l}-0.1443 * * * \\
(0.053)\end{array}$ \\
\hline Mlr & $\begin{array}{l}0.16 * * * \\
(0.0596)\end{array}$ & $\begin{array}{l}0.1503 * * * \\
(0.0581)\end{array}$ \\
\hline lfp & $\begin{array}{l}-0.0339 \\
(0.0402)\end{array}$ & $\begin{array}{l}-0.036 \\
(0.0388)\end{array}$ \\
\hline fr & $\begin{array}{l}-3.4456 * * * \\
(0.6008)\end{array}$ & $\begin{array}{l}-3.8854 * * * \\
(0.5608)\end{array}$ \\
\hline constant & $\begin{array}{l}67.8383 * * * \\
(13.4837)\end{array}$ & $\begin{array}{l}69.204 * * * \\
(13.1168)\end{array}$ \\
\hline R-squared & $\begin{array}{l}\text { within }=0.3794 \\
\text { between }=0.5251 \\
\text { overall }=0.4401\end{array}$ & $\begin{array}{l}\text { within }=0.3773 \\
\text { between }=0.5524 \\
\text { overall }=0.4451\end{array}$ \\
\hline F-Stat. F(6,111) & $11.31 * * *$ & na \\
\hline Wald chi2(6) & $\mathrm{Na}$ & $99.41 * * *$ \\
\hline Observations & 141 & 141 \\
\hline Number of groups & 24 & 24 \\
\hline
\end{tabular}

Note: $* * *$ significant at $1 \%$; **significant at 5\%; *significant at 10\%. Standard error-statistics are reported in parenthesis. na: Not applicable

As expected, table 2 shows that increase in $\mathrm{CO}_{2}$ emission (in kilotons) reduces life expectancy at birth at $1 \%$ significance level. A $1 \%$ increase in $\mathrm{CO}_{2}$ emission leads to a fall in life expectancy at birth by approximately 1.5 years in the fixed effects model and about 1.6 years in the random effects model. Contrary to expectation, 
findings show that increase in female literacy rate reduces life expectancy at birth at $1 \%$ significant level, while that of males will increase it also at the same level of significance. A $1 \%$ increase in female literacy rate leads to a fall in total life expectancy at birth by approximately 0.2 years in the fixed effects model and about 0.1 years in the random effects model. On the other hand, a 1\% increase in male literacy rate leads to a rise in life expectancy at birth by approximately 0.2 years in both the fixed and random effects model. Findings for males reflect a rise in life expectancy with improvements in literacy rate. Results for fertility rate follows expectation showing a fall in life expectancy at birth with a rise in the number of births per woman at $1 \%$ significance level. An increase in fertility rate by one birth leads to a fall in total life expectancy at birth, by approximately 4 years in the fixed and random effects model.

In Table 3, the result shows that increase in $\mathrm{CO}_{2}$ emission (in kilotons) leads to a rise in infant deaths at $1 \%$ significance level. A $1 \%$ increase in $\mathrm{CO}_{2}$ emission will raise infant mortality rate by approximately $0.1 \%$ in the fixed and random effects model.

Table 3 Effects of air pollution on infant mortality (per 1000 people)

Variables

\begin{tabular}{|l|}
\hline LNCO \\
\hline LIr \\
\hline Mlr \\
\hline fr \\
\hline constant \\
\hline
\end{tabular}

R-squared

F-Stat. $\mathrm{F}(6,111)$

Wald chi2(6)

Observations

Number of Groups

Hausman tests statistic

Fixed effects within regression model

$0.1337 * * *$
$(0.0424)$
$-0.1157 * *$
$(0.0473)$

\subsection{6}

$(0.0029)$

$-0.0054^{*}$

$(0.0032)$

$-0.0007$

$(0.0022)$

$0.3018^{* * *}$

$(0.0325)$

$4.3922 * * *$

(0.7302)

within $=0.6510$

between $=0.6937$

overall $=0.6814$

$34.51 * * * \quad \mathrm{~N}$

$\mathrm{Na}$

141

24

8.17
GLS-random effects model

\begin{tabular}{l}
$0.1381 * * *$ \\
$(0.0404)$ \\
$-0.12 * * *$ \\
$(0.0452)$ \\
0.0032 \\
$(0.0028)$ \\
-0.0048 \\
$(0.0031)$ \\
-0.0003 \\
$(0.0021)$ \\
$0.3172 * * *$ \\
$(0.0301)$ \\
$4.3236 * *$ \\
$(0.7016)$ \\
within $=0.6506$ \\
between $=0.7045$ \\
overall $=0.6824$ \\
Na \\
$274.12 * * *$ \\
141 \\
24 \\
\hline
\end{tabular}

Note: $* * *$ significant at $1 \% ; * *$ significant at $5 \%$; significant at $10 \%$. Standard error-statistics are reported in parenthesis na: Not applicable

The result also shows that increase in real GDP reduces infant mortality rate at $5 \%$ and $1 \%$ significance level in the fixed and random effects model respectively. A $1 \%$ increase in real GDP leads to a fall in infant deaths by approximately $1 \%$ in both models. Similarly, a rise in male literacy rate also reduces infant deaths only in the fixed effects model and at $10 \%$ significance level. A $1 \%$ increase in male literacy rate leads to a fall in infant mortality rate by about $0.005 \%$. The result for fertility rate shows a rise in infant mortality with an increase in the number of births per woman. Where fertility rate increases by one birth, infant mortality rate will rise by about $0.3 \%$ in both the fixed and random effects model.

\section{Discussion}

The findings of the study suggest that reducing air pollution remains an important step in improving health outcomes in SSA. The results show that $\mathrm{CO}_{2}$ emission significantly reduces life expectancy at birth and increases infant mortality rates in the region. The findings were expected as the toxicity of carbon emission in the environment and other forms of air pollution have harmful effects on human health. The presence of toxic substances in the air increases the prevalence of illness particularly respiratory and cardiovascular diseases. The susceptibility of infants to illness given that they have low health capital stock at very early stages of life increases the risk of mortality with a rise in air pollution (Grossman 1972 Grossman, 2000). Exposure to pollution also leads to depreciation in health capital stock even for the adult population which in turn reduces labor productivity and welfare. The effect in developing economies like SSA are significant given poor performing health system operations. The result is similar to those of earlier studies showing that air pollution is an important determinant 
of health outcomes (Correia et al. 2013; Lelieveld et al. 2015; Zang et al.2015; Yahaya 2016; Nakao et al.2017; Ebenstein et al. 2017; Jonson et al. 2017, Pinichka et al. 2017; Qi et al. 2018).

Findings for other predictor variables, show an inverse relationship between female literacy rate and life expectancy. This result can be associated with the pressure of combining work demands for educated females alongside with societal demands particularly for married females. On the other hand, findings for males reflecting positive relationship between literacy rate and life expectancy is expected as more education implies better involvement in the labor force and hence more income which is essential for male ego and societal acceptance.

Findings showing that reduction in the number of births per woman increases health condition follows from the fact that it somewhat induces less strain on financial resources to cater for health spending and other basic needs. Fall in fertility rate frees up resources that can be invested in promoting human and physical capital automatically translating to improvements in welfare and health (Prettner et al. 2013). Other results showing that improvements in real macroeconomic income translates to a fall in infant death are suggestive of increased allocation of health resources with income expansion. Therefore measures seeking to increase macroeconomic income somewhat achieves improvement in infant health.

In SSA, where health infrastructure is largely underdeveloped, reducing air pollution will be a significant progress towards improving health outcomes and accelerating progress towards the health-related Sustainable Development Goals (SDGs). It must be noted that while the findings of the current study provide evidence in support of reducing carbon emission, measures that promote use of cleaner sources of energy are also recommended as achieving economic progress to a great extent depends on the use of energy for industrial operations.

There are some limitations to this study, one of which is that most of the health outcome variables for SSA did not have enough time series observation which would have improved a panel data study as this one. There are also data limitation on $\mathrm{CO}_{2}$ emission from different energy sources that would have provided more findings for a study of this type. The proxies used in measuring health outcomes may not be exhaustive as information such as morbidity and disability are not captured. While these limitations may be the bases for future research, they do not invalidate the results of the current study.

\section{Conclusion}

This study examined the impact of air pollution on health status measured by life expectancy at birth and infant mortality rate in SSA using the fixed and random effects approach. The results provide evidence that poor air quality is associated with a significant fall in life expectancy at birth and increase in infant mortality rates. Findings suggest that the toxicity of carbon emission in the environment have significant harmful effects on human health. The results also indicate key roles of real income, literacy and fertility rate in advancing health conditions in the region.

The findings imply that existing poor health outcome in SSA are connected to poor air quality. In the bid to achieve the Sustainable Development Goal (SDG) on health, there is need for governments in the region to focus on reducing air pollution particularly with focus on measures that will encourage use of clean energy forms.

\section{References}

Baltagi B.H., Song S.H., Jung B.C, \& Koh W. (2007) "Testing for Serial Correlation, Spatial Autocorrelation and Random Effects”, Journal of Econometrics, 140: 5-51. 10.1016/j.jeconom.2006.09.001View Article Google Scholar.

Bollen, K. A. \& Brand, J. E. (2008), "Fixed and Random Effects in Panel Data Using Structural Equations Models" On-Line Working Paper Series California Center for Population Research.

Cameron A.C., \& Trivedi P.K. (2005), "Microeconometrics: Methods and Applications", Cambridge: Cambridge Press.View ArticleGoogle Scholar

Correia, W.A., Arden, P.C., Douglas, D. W., Yun W., Majid E., \& Francesca, D. (2013), "Effect of Air Pollution Control on Life Expectancy in the United States: An Analysis of 545 U.S. Counties for the Period from 2000 to 2007", Epidemiology, 24 (1) 23-31 doi: 10.1097/EDE.0b013e3182770237

Dahlgren G, \&Whitehead M. (1991), "Policies and Strategies To Promote Social Equity In Health", Stockholm: Institute for Futures Studies.

Ebenstein A, Fan M, Greenstone M3, He G, \& Zhou M. (2017), "New Evidence on The Impact of Sustained Exposure to Air Pollution on Life Expectancy From China's Huai River Policy", Proc Natl Acad Sci U S A. 26;114(39):10384-10389, doi: 10.1073/pnas.1616784114. Epub 2017 Sep 11.

Farag M., Nandakumar A. K., Wallack S., Hodgkin D., Gaumer G. \& Erbil C.(2013), "Health Expenditures, Health Outcomes and The Role of Good Governance", Erbil Int J Health Care Finance Econ 13, 33-52 DOI 10.1007/s10754-012-9120-3.

Giovanis E. \& Ozdamar O. (2018), "Health Status, Mental Health and Air Quality: Evidence from Pensioners in Europe", Environmental Science and Pollution Research 25, (14), 14206-14225. 
Grossman, M. (1972a), “On the Concept of Health Capital and the Demand for Health", Journal of Political Economy, 80, 223-255.

Grossman, M. (2000), “The Human Capital Model”, In J. e. Culyer A.J. Newhouse, Handbook of Health Economics. Vol 1A. Elsevier, Amsterdam.

Gupta, I. \& Mitra A. (2004), "Economic Growth, Health and Poverty: an Exploratory Study for India", Development Policy Review, 22,193-206.

Hausman, J.A. (1978), "Specification Tests in Econometrics", Econometrica 46 (6), 1251-1271.

Jonson, J.E., Borken-Kleefeld J., Simpson, D., 'rri1, A., Posch, M \& Heyes, C. (2017), "Impact of excess NOx Emissions from Diesel Cars on Air Quality Public Health and Eutrophication in Europe", Environ. Res. Lett. 12094017

Landrigan, P.J., Fuller, R., Acosta, N.J.R., Adeyi, O., Arnold, R., Basu, N., Baldé, A.B., Bertollini, R., BoseO'Reilly, S., \& Boufford, J.I. et al. (2018), "The Lancet Commission on Pollution and Health", Lancet, 391(10119):462-512. doi: 10.1016/S0140-6736(17)32345-0.

Lelieveld J., Evans, J. S., Fnais M., Giannadaki D \& Pozzer A. (2015), “The Contribution of Outdoor Air Pollution Sources to Premature Mortality on a Global Scale", Nature 525, 367-371

Li F, Liu Y, Lü J, Liang L, \& Harmer P. (2015), "Ambient air pollution in China poses a Multifaceted Health Threat to Outdoor Physical Activity", J Epidemiol Community Health, 69(3):201-204

Li M., \& Mallat, L (2018), "Health impacts of air pollution", SCOR Paper \#42

Liu, W.., Xu Z \& Yang, T. (2018), "Health Effects of Air Pollution in China”, Int. J. Environ. Res. Public Health 5,1471

Maisonneuve C., Serra R.N., Murtin F. \& Martins J.O. (2017), “The Role of Policy and Institutions on Health Spending", Health Econ, 26, 834-843

Mannucci, M.P., \& Franchini M. (2017), "Health Effects of Ambient Air Pollution in Developing Countries", Int. J. Environ. Res. Public Health, 14, 1048; doi:10.3390/ijerph14091048

Montt G. (2018), "The Gendered Effects of Air Pollution on Labour Supply" ILO Research Department Working Paper No. 27

Mukhopadhyay K. \& Forssell, O. (2005), "An Empirical Investigation of Air Pollution from Fossil Fuel Combustion and Its Impact on Health in India during 1973-1974 to 1996-1997”, Ecological Economics, 55, $235-250$

Nakao, M. Yamauchi1, K., Ishihara Y., Omori, H., Ichinnorov D \& Solongo, B. (2017), "Effects of Air Pollution and Seasons on Health-Related Quality of Life of Mongolian Adults Living in Ulaanbaatar: Cross-Sectional Studies", BMC Public Health, 17,594

Pinichka, C., Makka N., Sukkumnoed D., Chariyalertsak, S., Inchai1, P., \& Bundhamcharoen K. (2017), "Burden of Disease Attributed to Ambient Air Pollution in Thailand: A GIS-based approach", PLOS ONE https://doi.org/10.1371/journal.pone.0189909

Pitt, M., M. Rosenzweig, \& Hassan M.N. (2006), "Sharing the Burden of Disease: Gender, the Household Division of Labor and the Health Effects of Indoor Air Pollution" Mimeo.

Plumper T. \& Neumayer E. (2013), "Health Spending, Out-of-Pocket Contributions, and Mortality Rates", Public Administration 91 (2) 403-418. doi: 10.1111/j.1467-9299.2012.02039.x

Prettner, K., Bloom, D. E \& Strulik, H. (2013), "Declining Fertility and Economic Well-Being: Do Education and Health Ride to The Rescue?”, Labour economics, 22, 70-79. doi:10.1016/j.labeco.2012

Qiu Y., Yang, F., \& Lai W. (2018), "The Impact of Indoor Air Pollution on Health Outcomes and Cognitive Abilities: Empirical evidence from China", Conference paper presented at the American Economic Association annual meeting held in Philadelphia on January 5-7, Available at https://www.aeaweb.org/conference/2018/preliminary/paper/GkHf7syi

Rajkumar A.S., \& Swaroop V. (2008), "Public Spending and Outcomes: Does governance matter?", Journal of Development Economics, 86, 96-111.

Romley, J. A., Andrew H \& Dana P. G, (2012), “The Impact of Air Quality on Hospital Spending”, Santa Monica, CA: RAND Corporation, 2010. https://www.rand.org/pubs/technical_reports/TR777.html. Also available in print form.

WHO (2014) "Burden of Disease from Household Air Pollution for 2012", http://doi.org/10.1016/ S01406736(12)61766-8.Smith

WHO (2016), "Ambient air pollution: A Global Assessment of Exposure and Burden of Disease”, Retrieved from https://www.who.int/phe/publications/air-pollution-global-assessment/en/

WHO (2019), "Air pollution and Health", WHO News Letter Retrieved from https://www.who.int/airpollution/en/

WHO (2019) , "WHO Global Ambient Air Quality Database (update 2018)", Retrieved from https://www.who.int/airpollution/data/cities/en/

Wooldridge, J. (2002), "Econometric Analysis of Cross-Section and Panel Data", Cambridge, MA: MIT Press. 
World Bank (2018), "World Development Indicators", Data Catalogue.

Yahaya A., Mohamed N. N., Shah, M. H., Ghani, H.A., \& Noor M. Z., (2016) "How Relevant is Environmental Quality to Per Capita Health Expenditures? Empirical Evidence from Panel of Developing Countries", DOI 10.1186/s40064-016-2505-x SpringerPlus 5, 925

Zerbo E. (2015) " $\mathrm{CO}_{2}$ Emissions, Growth, Energy Consumption and Foreign Trade in Sub-Sahara African countries", hal-01110769

Zhang, X., Zhang, X., \& Chen, X. (2015) "Happiness in the Air: How Does a Dirty Sky Affect Subjective Wellbeing?”, IZA Discussion Paper No. 9312

\section{Appendix}

Histogram for Infant mortality rates and life expectancy.

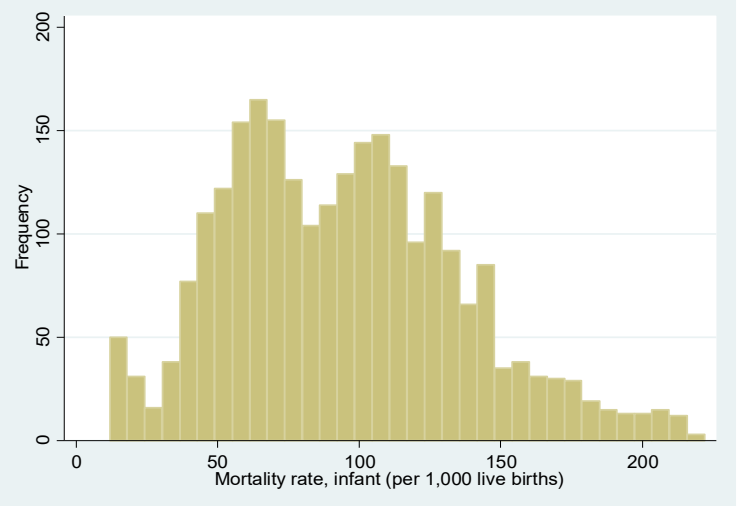

A

Infant mortality somewhat skewed to the left in figure A, Natural log values are more normal (Figure B)

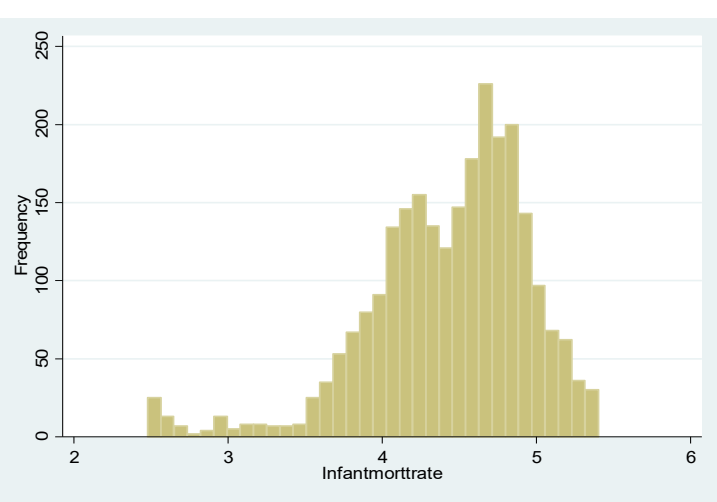

B

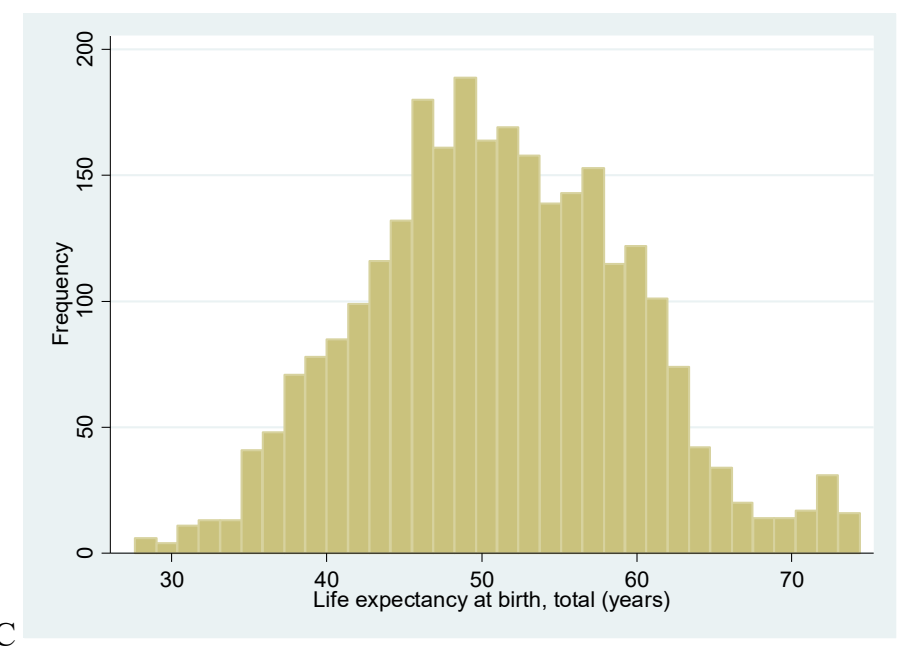

Non logarithmic value for Life expectancy relatively normal compared to infant mortality. The log of infant mortality was used for the analysis while non-logarithmic values were used for life expectancy. 